\title{
Antibiograms of avian pathogenic Escherichia coli isolates from commercial layers with colibacillosis in Southwest Nigeria
}

\section{Ayodeji Oluwadare Olarinmoye ${ }^{1^{*}}$, Oludotun Olubusola Oladele ${ }^{2}$, Adekunle Adeluyi Adediji $^{2}$, Uchenna Godwin Ntiwunka ${ }^{2}$ and Grace Oluwatoyin Tayo ${ }^{1}$}

\author{
${ }^{1}$ School of Agriculture and Industrial Technology, Department of Animal Science, Babcock University, llisan Remo, PMB \\ 21244, Ikeja, Lagos, Nigeria. \\ ${ }^{2}$ Animal Care Services Konsult (Poultry and Fish Diseases) Diagnostic Laboratory, Ogere Remo, Ogun State, Nigeria. \\ Email: aolarinmoye@gmail.com
}

Received 19 April 2013; Received revised form 19 May 2013; Acceptance 13 June 2013

\begin{abstract}
Aims: This study investigated the antibiotic susceptibilities of avian pathogenic Escherichia coli (APEC) isolates from layer chickens that died of colibacillosis, in the 6 states of Southwest Nigeria.

Methodology and results: From bacteriological cultures of dead layers with suspected colibacillosis, 509 APEC isolates were identified by Gram staining, microscopy, and biochemical reactions, and tested by the Kirby-Bauer disc diffusion method for susceptibility to 9 human and veterinary antibiotics: Streptomycin (Str, $200 \mu \mathrm{g}$ ); Nitrofurantoin (Nit, $300 \mu \mathrm{g}$ ); Augmentin (Aug, $30 \mu \mathrm{g}$ ); Amoxicillin (Amo, $25 \mu \mathrm{g}$ ); Chloramphenicol (Chl, $30 \mu \mathrm{g})$; Gentamicin (Gen, $10 \mu \mathrm{g}$ ); Tetracycline (Tet, $25 \mu \mathrm{g}$ ); Ofloxacin (Ofl, $5 \mu \mathrm{g}$ ); and Fosfotrim (Fos, $30 \mu \mathrm{g}$ ). The APEC isolates were highly resistance to Amo $(99.2 \%)$, Chloramphenicol $(96.5 \%)$, Tet $(91.4 \%)$ and Ofl $(86.4 \%)$; moderately resistant to Gen $(67.2 \%)$, Aug $(63.5 \%)$, Nit $(51.7 \%)$ and Fos (37.9\%); while $14.3 \%$ of the isolates were resistant to Str at the test concentration of 200 $\mu \mathrm{g}$, equivalent to ten times the normal disc test concentration. Overall, 39 antibiotic resistance patterns were observed, and more than $84.68 \%(n=431)$ of the APEC isolates were multi-drug resistant.

Conclusion, significance and impact of study: These results indicate that there is widespread misuse of antimicrobials in the poultry industry in Southwest Nigeria, and portend a high failure rate for the treatment of avian colibacillosis in the region. Owing to the public health importance of multidrug resistant bacteria that arise from animal production systems, there is need for exhaustive review of the regulatory framework guiding the supply and use of veterinary antimicrobials in Nigeria.
\end{abstract}

Keywords: APEC, layers, drug-resistant, SW Nigeria

\section{INTRODUCTION}

Most Escherichia coli are non-pathogenic, and comprise part of the microflora of the colon of reptiles, birds and mammals. However, Avian Pathogenic Escherichia coli (APEC) serotypes as a group are virulent for birds, and are the causative agents of avian colibacillosis. APEC serotypes affect all age groups of susceptible birds ranging from chicks to adult layers, broilers and breeders. These APEC infections are the chief cause of morbidity, lowered productivity and higher mortality rates of affected poultry flocks (Dho-Moulin and Fairbrother, 1999; Alterkruse et al., 2002; Barnes et al., 2003; Ewers et al., 2003). APEC infections in early embryonic life translate to a high number of dead in shell embryos and reduced hatchability of fertile eggs (Raji et al., 2003). In Nigeria, $E$. coli serotypes O8:K50, O9:K30, O26:K60 and O78:K80, have been identified in clinical cases of colibacillosis or from poor hatches characterized by high numbers of dead in shell embryos (Raji et al., 2007).

APEC infections may be introduced to susceptible birds via contaminated feed, water, dust, and litter materials (Nivas et al., 1977; Dho-Moulin and Fairbrother, 1999). Chicks may acquire the infection from unsanitary hatchery equipment and premises. APEC strains may also be passed on to chicks when a developing egg is contaminated in the reproductive tract or cloaca of a carrier hen (Barnes and Gross, 1997). The clinical course of avian colibacillosis depends on the virulence of the eliciting APEC strain. Thus, the disease varies from a peracute and rapidly fatal septicemia with little or no clinical signs, to a subacute or mild disease, or an acute form with signs including sudden onset of dyspnea, depression and prostration ending in death, or a chronic infection characterized by a gradual onset of anorexia, unthriftness, diarrhea and progressive emaciation that is 
described by farmers as the "sick bird syndrome". The usual clinical signs of avian colibacillosis in chicks (mushy chick syndrome) include somnolence, lethargy, anorexia, diarrhea, failure to groom, and a tendency to huddle together near the heater in the brooder premises. Affected chicks start to die within $24 \mathrm{~h}$ and mortalities attain a peak at about the $5^{\text {th }}$ to $7^{\text {th }}$ day post-hatching. Typical lesions of avian colibacillosis observed at postmortem include facial cellulitis (swollen head syndrome), omphalitis (yolk sac infection), air sacculitis, peritonitis, pericarditis, salpingitis, synovitis and coligranuloma or Hjarre's disease (Barnes and Gross, 1997; Dho-Moulin and Fairbrother, 1999).

\section{APEC virulence factors}

APEC serotypes possess virulence factors that act to evade the activity of heterophils (Mellata et al., 2003). These virulence factors favor egress of the pathogen from its primary portal of entry and localization in the nasopharynx, into the general circulation of infected birds from where it establishes septicemia. APEC virulence factors include: Types 1 (F1A) and P (F11) fimbriae; curli (i.e. the aerobactin iron-sequestering system); K1 capsular antigen; temperature-sensitive haemagluttinin (Tsh); and resistance to the bactericidal effect of serum (Dho-Moulin and Fairbrother, 1999); the 0-min, group of unique chromosomal regions (Brown and Curtiss III, 1996); and putative virulence genes including cvaC, iroN, iss, iut $A$, sit $A$, tsh, fyuA, irp2, and ompT that are harbored in the large APEC plasmid known as pTJ100 (RodriguezSiek et al., 2005). The ability of APEC to evade the effects of several antimicrobials is yet another virulence enhancing mechanism and it is mediated by the plasmids IncA/C, IncP1-a, IncF, and Incl1, that carry multidrug resistance (MDR) encoding genes (Johnson et al., 2012).

There have been several reports of the involvement of MDR APEC isolates in cases of avian collibacillosis in Nigeria, but the samples used were limited to quite a few farms (Orajaka and Mohan, 1986; Raji et al., 2003; Raji, et al., 2007; Ogunleye et al., 2008; Mamza et al., 2010). The aim of this study was to determine the antibiotic susceptibilities of APEC isolates from a wider location within the southwest geopolitical zone of Nigeria, comprising Lagos, Oyo, Ogun, Osun, Ondo and Ekiti in SW Nigeria. The economic and public health implications of drug resistant APEC phenotypes are highlighted and the strategy for prevention of avian colibacillosis in the study area is discussed.

\section{MATERIALS AND METHODS}

\section{Study location (SW Nigeria)}

A distinct geopolitical zone comprising 6 contiguous States: Lagos (6 $\left.6^{\circ} 31^{\prime} 23.8^{\prime \prime} \mathrm{N} \quad 3^{\circ} 32^{\prime} 26.85^{\prime \prime} \mathrm{E}\right)$; Ondo $\left(6^{\circ}\right.$ 53' 45.35" N 4० 53' 36.83" E); Ogun (6 $6^{\circ} 54^{\prime} 35.4^{\prime \prime} \mathrm{N} \quad 3^{\circ}$ $\left.15^{\prime} 30.11^{\prime \prime} \mathrm{E}\right)$; Osun (7० $\left.35^{\prime} 15.3^{\prime \prime} \mathrm{N} 4^{\circ} 33^{\prime} 44.79^{\prime \prime} \mathrm{E}\right)$; Ekiti (7०39' 56.09" N $\left.5^{\circ} 18^{\prime} 36.9^{\prime \prime} \mathrm{E}\right)$ and Oyo (8 $8^{\circ} 7^{\prime}$ $\left.10.44^{\prime \prime} \mathrm{N} 3^{\circ} 25^{\prime} 10.39 " \mathrm{E}\right)$. Bounded by the Atlantic Ocean to the South, the South-East border of the Republic of Benin to the West, Kwara and Kogi States to the North, Edo State to the East, and Delta State to the South-East (Figure 1), the SW States of Nigeria jointly occupy $8.42 \%$ of the total land area of Nigeria. In 2006, the combined human population of the region was estimated at 27,722,432 (National Population Commission, 2010). The climate of SW Nigeria consists of two major annual seasons: a bimodal rainy season, and the dry harmattan season characterized by very low precipitation, a dusty haze and generally poor visibility. The vegetation zones include salt and fresh water mangrove swamps, rainforests, and the Guinea Savannah characterized by tall grasses interspersed with trees (lloeje, 2001). In Nigeria, the principal sources of various breeds of exotic parent stock and commercial day old chicks are the SW States (Adene and Oguntade, 2006).

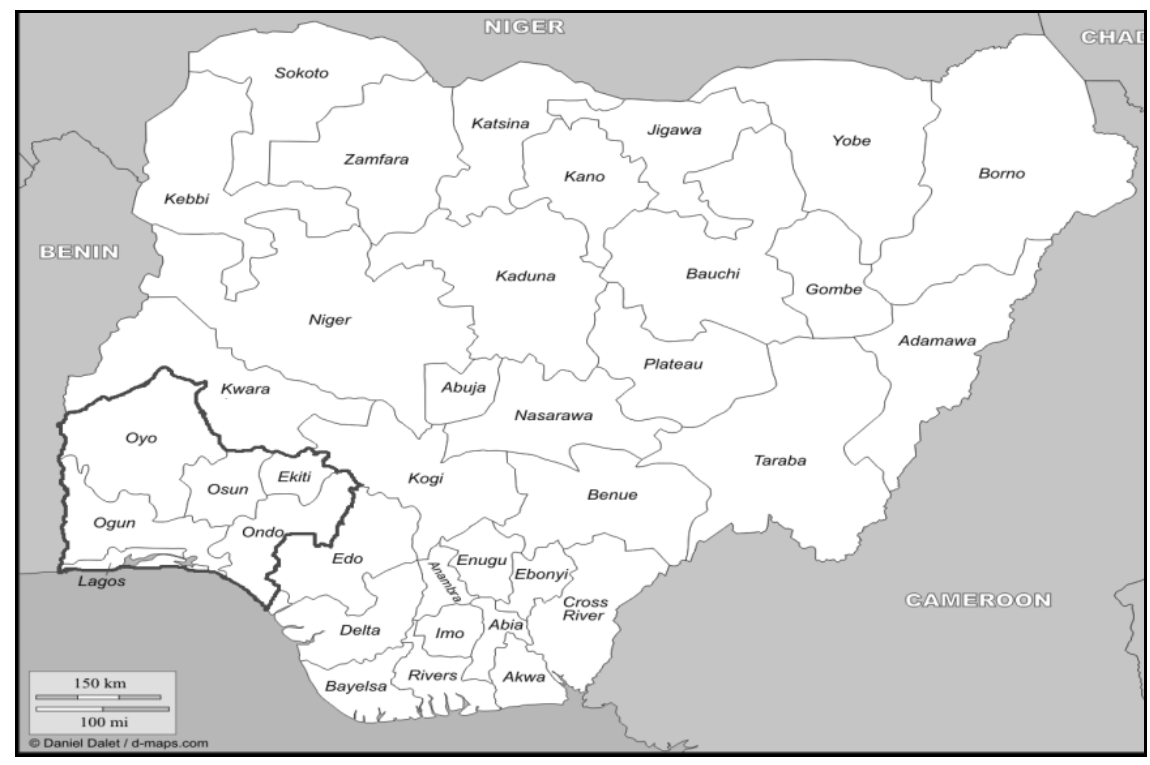

Figure 1: Map of Nigeria with the six southwestern states highlighted (Source: Dalet, 2013). 
Farmers' preference for commercial poultry production in SW Nigeria has been attributed partly to the scarcity of land in the region, and the relative ease with which large flocks of birds can be raised in confinement (Olarinmoye et al., 2011).

\section{Sampling procedure}

Following repeated farm outbreaks of a poultry disease with clinical signs resembling colibacillosis between May and September 2009, this study was done to detect the aetiology of the condition. Fresh samples of dead chickens were randomly selected from batches received from 707 commercial poultry farms scattered across Oyo, Ogun, Ondo, Osun, Lagos and Ekiti States. The sampling procedure was highly randomized to ensure the representativeness of the chosen birds. The carcasses were promptly necropsied according to the standard procedure described by Lowenstine (1986). Briefly, each carcass was examined externally for signs of colibacillosis including facial cellulitis, conjunctivitis, nasal discharges, and arthritis (especially of the hock joint), and for signs of management problems e.g. cachexia, pecking wounds and cage strangulation. The carcass was then opened up and inspected for internal lesions including tracheitis, air sacculitis, pneumonia, pericarditis, hepatitis, oophoritis, salpingitis and egg bound peritonitis (an inflammation of the peritoneum and reproductive tract of laying birds). With sterile swabs, samples of the heart blood, oro-nasal exudates, joint fluids and lesions of affected organs (liver, spleen, gall bladder, air sac, heart, pericardium, ovary and oviduct) were aseptically collected for bacteriological analysis.

\section{APEC isolation and identification technique}

The specimen swabs were streaked directly on sterile MacConkey (MCA) agar plates (Oxoid Ltd., Detroit, Michigan, USA) and the inoculated plates were incubated at $37^{\circ} \mathrm{C}$ aerobically for $24 \mathrm{~h}$. A tentative case diagnosis of avian colibacillosis was based on the appearance on the MCA culture plates, of a preponderance of colonies resembling $E$. coli (with a convex shape, dark pink color, entire edges and a diameter of 2-4 mm). From the $24 \mathrm{~h}$ cultures, 2 to 3 representative colonies of $E$. coli were selected with a sterile inoculating loop and sub-cultured twice on eosin methylene blue (EMB) agar (Oxoid Ltd., Detroit, Michigan, USA) at $37{ }^{\circ} \mathrm{C}$, aerobically for $24 \mathrm{~h}$. Several colonies measuring 1-2 $\mathrm{mm}$ in diameter and with a characteristic metallic green sheen resembling that of $E$. coli were observed on the EMB plates. Further confirmation of E. coli was according to Krieg et al. (1984), and based on gram staining, and biochemical tests (catalase, oxidase, indole, methyl red, Voges-Proskauer test, citrate utilization, nitrate reduction, $\mathrm{H}_{2} \mathrm{~S}$ production in TSI, gelatin liquefaction and urease test).

\section{Antimicrobial susceptibility test}

The standard disc diffusion test was performed according to the recommendations of the Clinical Laboratory Standards Institute (CLSI, 2006). Four to five well separated colonies of $E$. coli were selected from the EMB agar plates with a sterile inoculating loop, suspended in 2 $\mathrm{mL}$ of sterile normal saline in a tube, and vortexed to obtain a uniform mixture. The turbidity of the mixture was adjusted to 0.5 McFarland Standard by adding more organism if the suspension was found to be too light, or by further dilution with sterile saline if the suspension was too heavy. A sterile cotton swab was dipped into the standardized suspension of $E$. coli, and streaked evenly across the surface of Müller-Hinton (MH) agar to produce a uniform growth of the organism. With sterile forceps, 9 commercial antibiotic discs were placed on the surface of the inoculated $\mathrm{MH}$ agar and the plates were incubated at $37{ }^{\circ} \mathrm{C}$, aerobically for $18 \mathrm{~h}$. The antibiotics used were: streptomycin (Str, $200 \mu \mathrm{g}$ ); nitrofurantoin (Nit, $300 \mu \mathrm{g}$ ); augmentin (Aug, $30 \mu \mathrm{g}$ ); amoxicillin (Amo, $25 \mu \mathrm{g}$ ); chloramphenicol (Chl, $30 \mu \mathrm{g}$ ); gentamicin (Gen, $10 \mu \mathrm{g}$ ); tetracycline (Tet, $25 \mu \mathrm{g}$ ); and ofloxacin (Ofl, $5 \mu \mathrm{g}$ ) - Abtek Biologicals Ltd., UK; and fosfotrim (Fos, $30 \mu \mathrm{g}$ ) Investigación Aplicada S. A., Mexico. The antibiotic classes represented by these drugs are: aminoglycosides (streptomycin, gentamicin); potentiated phosphonates (Fosfotrim); nitrofurans (nitrofurantoin); $\beta$-lactam $+\beta$ lactam inhibitor (augmentin); fluoroquinolones (ofloxacin); tetracyclines (tetracycline); fenicols (chloramphenicol); $\beta$ lactam (amoxicillin).

Measurement and interpretation of the zones of growth inhibition on agar induced by the presence of these antibiotics, was according to CLSI standards for agar disc diffusion test (CLSI, 2006). However, inhibition zones for fosfotrim were interpreted according to the manufacturer's recommendations.

\section{Interpretation of susceptibility test results}

APEC isolates that are resistant to a minimum of three classes of antibiotics are regarded as MDR strains. Prevalence of antibiotic resistance among the APEC isolates was calculated as the percentage of isolates that showed resistance to one or more of the test antibiotics, according to the formula (Percentage Resistance = Number of resistant isolates/Number of isolates tested with the antibiotic $x$ 100). According to Krumperman (1983), the Multiple Antibiotic Resistance (MAR) index of each isolate is calculated as a ratio $(a / b)$ were ' $a$ ' is the number of antibiotics to which the isolate is resistant and ' $b$ ' is the total number of antibiotics to which it is exposed. Adeleke and Omafuvbe (2011), described an isolate with MAR index less than or equal to 0.2 as one from a farm where antibiotics were used infrequently, while one with MAR index higher than 0.2 is from a farm where antibiotics were used more frequently.

\section{Statistical Analysis}

Data entry and analysis was performed with Microsoft Excel 2010. Descriptive statistics comprising percentages were used to indicate the proportion of layer farms affected by avian colibacillosis and other bacterial diseases; the frequency of isolation of APEC and other pathogenic bacteria from septicaemic lesions of dead birds; and the prevalence of resistance to antibiotics amongst APEC isolates in SW Nigeria. Summary data were presented as tables and a bar chart. 


\section{RESULTS}

The prevalence of APEC infections in commercial layers

Overall, $59.55 \%$ (421 out of 707 farms) were confirmed with outbreaks of avian colibacillosis due to one or more APEC strains (Table 1). Bacteriological cultures of necropsy specimens from chickens with suspected colibacillosis yielded a total of 509 APEC isolates, and 429 isolates of other pathogenic bacteria including
Staphylococcus aureus, Streptococcus spp., Klebsiella spp., Salmonella spp., Pseudomonas spp., Enterobacter spp., and Corynebacterium spp. (Table 2). A breakdown of the numbers of these pathogenic bacteria shows that apart from E. coli, the next most numerous were mixed Staphylococcus aureus and Streptococcus spp. isolates (21.1\%), followed by Klebsiella spp. (17.69\%). Occurring at lower frequencies were Salmonella spp. (2.88\%), Pseudomonas spp. (2.03\%), Enterobacter spp. (1.71\%), and Corynebacterium spp. (0.32\%) (Table 3).

Table 1: The proportion of commercial layer farms affected by avian colibacillosis and other bacterial diseases in SW Nigeria.

\begin{tabular}{lccc}
\hline Date & $\begin{array}{c}\text { Poultry farms affected by } \\
\text { avian colibacillosis }\end{array}$ & $\begin{array}{c}\text { Poultry farms with flocks affected by } \\
\text { other pathogenic bacteria. }\end{array}$ & Total \\
\hline May 2009 & 82 & 75 & 157 \\
June 2009 & 119 & 73 & 192 \\
July 2009 & 112 & 70 & 182 \\
August 2009 & 108 & 68 & 176 \\
Total & $421(59.55 \%)$ & $286(40.45 \%)$ & $707(100 \%)$ \\
\hline
\end{tabular}

Table 2: The frequency of isolation of APEC and other bacteria from dead layers in SW Nigeria.

\begin{tabular}{lccc}
\hline Date & APEC & Other pathogenic bacteria of poultry & Total \\
\hline May 2009 & 106 & 138 & 244 \\
June 2009 & 145 & 73 & 218 \\
July 2009 & 134 & 127 & 261 \\
August 2009 & 124 & 91 & 215 \\
Total & $509(54.26 \%)$ & $429(45.74 \%)$ & $938(100 \%)$ \\
\hline
\end{tabular}

Table 3: The contribution of $E$. coli and other pathogenic bacteria to poultry bacteriosis in SW Nigeria.

\begin{tabular}{lcc}
\hline Name & Total number of isolates & Frequency of isolation (\%) \\
\hline Corynebacterium spp. & 3 & 0.32 \\
Enterobacter spp. & 16 & 1.71 \\
Pseudomonas spp. & 19 & 2.03 \\
Salmonella spp. & 27 & 2.88 \\
Klebsiella spp. & 166 & 17.69 \\
Mixed Staphylococcus aureus and & 198 & 21.11 \\
Streptococcus spp. infections & 509 & 54.26 \\
Escherichia coli & 938 & 100 \\
Total & & \\
\hline
\end{tabular}

\section{The prevalence of antibiotic resistance amongst APEC isolates in SW Nigeria}

The antibiograms of 509 APEC isolates from SW Nigeria is as shown in Figure 2. The isolates were highly resistant to amoxicillin (99.2\%), chloramphenicol (96.5\%), tetracycline $(91.4 \%)$, and ofloxacin $(86.4 \%)$; moderately resistant to gentamicin (67.2\%), augmentin (63.5\%), nitrofurantoin $(51.7 \%)$ and fosfotrim $(37.9 \%)$; and least resistant to streptomycin (14.3\%). The results also show that between $0.2 \%$ to $14.93 \%$ of the APEC isolates exhibited intermediate resistance/susceptibility to Streptomycin, fosfotrim, nitrofurantoin, augmentin, amoxicillin, chloramphenicol, gentamicin, tetracycline, and ofloxacin.

\section{Antibiotic resistance patterns of APEC strains from SW Nigeria}

The 509 APEC isolates exhibited a total of 39 resistance patterns to the nine tested antibiotics. Seventy-eight out of 509 APEC isolates (15.32\%) had a MAR Index $\leq 0.2$, 
being resistant to 1 and not more than 2 classes of antibiotics. The remaining APEC isolates $(n=431$ or $84.68 \%$ ) were MDR phenotypes that exhibited resistance to a minimum of three antibiotics (MAR Index $\geq 0.2$ ). On the whole, around one-third of all the APEC isolates $(33.22 \%)$ were pan-resistant to all the eight classes of antibiotics tested. The most prevalent MDR phenotypes were: Tet-Chl-Amo (43 isolates); Aug-Gen-Ofl-Tet-ChlAmo (48 isolates); Ofl-Tet-Chl-Amo (82 isolates); Str-FosNit-Aug-Amo-Chl-Gen-Tet-Ofl (53 isolates); Fos-Nit-AugGen-Ofl-Tet-Chl-Amo (116 isolates), (Table 4).

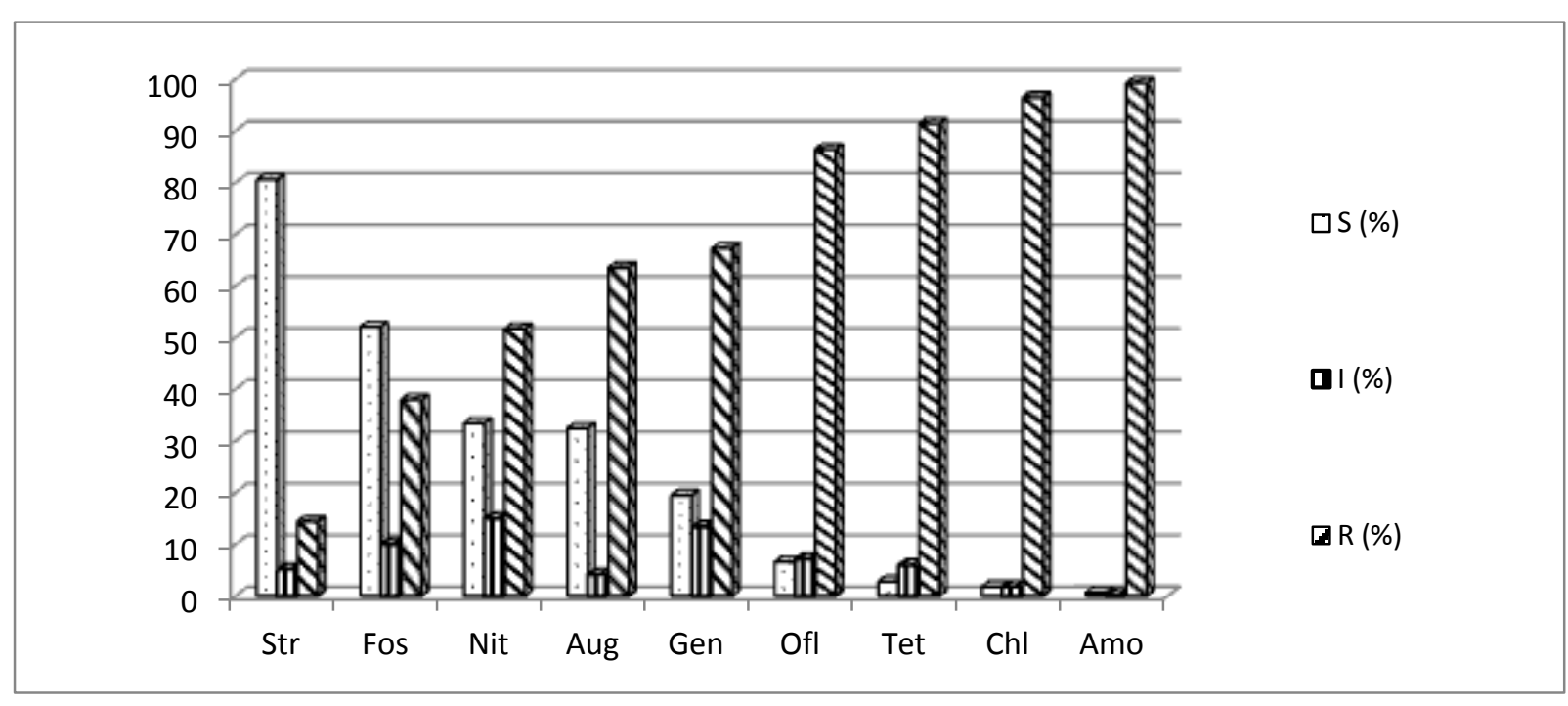

Figure 2: Antibiotic susceptibility profiles of the APEC isolates from commercial layers in SW Nigeria. S (sensitive); I (intermediate); R (resistant); Str (streptomycin); Nit (nitrofurantoin); Aug (augmentin); Amo (amoxicillin); Chl (chloramphenicol); Gen (gentamicin); Tet (tetracycline); Ofl (Ofloxacin); Fos (fosfotrim).

\section{DISCUSSION}

Our findings show that in SW Nigeria, colisepticaemia (the peracute or acute form of avian colibacillosis) is the most frequent bacterial cause of death in commercial layers and by extension the most economically important bacterial disease of layers in the region. According to Gross (1994), colibacillosis is a major cause of economic losses to the poultry industry throughout the world, and this is due to the reduced productivity and mortalities of affected flocks. Our isolations of Staphylococcus aureus and Streptococcus spp., Klebsiella spp., Pseudomonas spp., Enterobacter spp., Corynebacterium spp. and E. coli, from the blood and internal lesions of dead chickens is similar to the isolations reported by Dashe et al. (2012). Most strains of these genera of bacteria comprise part of the avian commensal microflora and would only cause disease in immunocompromised birds (Wray and Davies, 2001). Stress plays a key role in this regard, and subclinical forms of Infectious Bursal Disease (Gumboro), Newcastle disease, Mycoplasmosis, Infectious bronchitis, and Coccidiosis are common stressors of poultry species (Wray and Davies, 2001). Genetic predisposition to stress is also well known, and highly inbred lines or exotic poultry are more susceptible to stress and thus to opportunistic bacterial infection (Huff et al., 2005). Other oft-neglected stress inducing factors that can predispose poultry to opportunistic infections include: poorly constructed or overcrowded housing, poor vaccine coverage against preventable viral, mycoplasma and protozoan diseases; and poor nutrition. According to Niilo and Bezeau (1961), a combination of factors including poor management, unhygienic conditions and nutritional deficiencies (e.g. avitminosis A) can aid the natural outbreak of diseases caused by pathogenic organisms such as Pseudomonas aeruginosa.

This study has revealed a very high prevalence of APEC with resistance to Amo, Chl and Tet $(99.2 \%$, 96.5\%, $91.4 \%$ respectively), in SW Nigeria. These values are similar to those reported by Raji et al. (2007), for APEC isolates from clinical cases of colibacillosis in Zaria, northern Nigeria (Amo, 65\%; Chl, 70\%; Tet, 60\%), but are much higher than the prevalence figures reported by Hasan et al. (2011) for antibiotic resistant APEC strains from Bangladesh (Amo, 18\%; Chl, 8.9\%; Tet,45.5\%). These variations in antibiotic resistance across locations may be due to differences in the patterns of usage of these drugs in different regions (and Ojo, 2007). Selection pressure for the development of MDR plasmids in the gut flora of birds is driven by the routine addition of antibiotics to poultry feed and water for disease prevention and growth promotion (Bager et al., 1997; Van den Bogaard and Stobberingh, 1999). Similar condition may exist with the administration of human antibiotics to poultry (Okoli et al., 2002); and the use of poultry feeds contaminated with MDR bacteria (Okonko et al., 2010; Ezekiel et al., 2011). Our findings of high prevalence rates for APEC resistance to Tet, Str, Nit, Chl and to Ofl in SW Nigeria, point to a growing trend of heavier usage and misuse of these antibiotics. 
Table 4: Antibiotic resistance patterns of APEC isolates from SW Nigeria.

\begin{tabular}{|c|c|c|c|c|}
\hline Resistance pattern & Antibiotic classes & Isolates & MAR Index & Total \\
\hline Chl & 1 & 2 & 0.1 & \multirow{15}{*}{$\begin{array}{c}78 \text { APEC Strains } \\
\text { with MAR Index } \\
\leq 0.2\end{array}$} \\
\hline Tet & 1 & 2 & 0.1 & \\
\hline Gen & 1 & 3 & 0.1 & \\
\hline Ofl & 1 & 7 & 0.1 & \\
\hline Nit & 1 & 12 & 0.1 & \\
\hline Aug & 1 & 13 & 0.1 & \\
\hline Amo & 1 & 17 & 0.1 & \\
\hline Gen-Ofl & 2 & 1 & 0.2 & \\
\hline Tet-Chl & 2 & 1 & 0.2 & \\
\hline Ofl-Tet & 2 & 1 & 0.2 & \\
\hline Nit-Aug & 2 & 2 & 0.2 & \\
\hline Tet-Amo & 2 & 2 & 0.2 & \\
\hline Ofl-Chl & 2 & 3 & 0.2 & \\
\hline Chl-Amo & 2 & 4 & 0.2 & \\
\hline Aug-Gen & 2 & 8 & 0.2 & \\
\hline Aug-Gen-Chl & 3 & 1 & 0.3 & \multirow{24}{*}{$\begin{array}{l}431 \text { APEC } \\
\text { Strains with MAR } \\
\text { Index } \geq 0.2\end{array}$} \\
\hline Nit-Chl-Amo & 3 & 1 & 0.3 & \\
\hline Ofl-Tet-Amo & 3 & 1 & 0.3 & \\
\hline Ofl-Chl-Amo & 3 & 6 & 0.3 & \\
\hline Tet-Chl-Amo & 3 & 43 & 0.3 & \\
\hline Aug-Gen-Chl-Amo & 4 & 1 & 0.4 & \\
\hline Nit-Aug-Gen-Chl & 4 & 1 & 0.4 & \\
\hline Gen-Ofl-Chl-Amo & 4 & 5 & 0.4 & \\
\hline Ofl-Tet-Chl-Amo & 4 & 82 & 0.4 & \\
\hline Aug-Gen-Ofl-Chl-Amo & 5 & 1 & 0.6 & \\
\hline Aug-Ofl-Tet-Chl-Amo & 5 & 1 & 0.6 & \\
\hline Fos-Nit-Aug-Chl-Amo & 5 & 1 & 0.6 & \\
\hline Nit-Gen-Ofl-Chl-Amo & 5 & 1 & 0.6 & \\
\hline Str-Ofl-Tet-Chl-Amo & 5 & 2 & 0.6 & \\
\hline Gen-Ofl-Tet-Chl-Amo & 5 & 17 & 0.6 & \\
\hline Fos-Nit-Aug-Gen-Chl-Amo & 6 & 1 & 0.7 & \\
\hline Nit-Gen-Ofl-Tet-Chl-Amo & 6 & 7 & 0.7 & \\
\hline Aug-Gen-Ofl-Tet-Chl-Amo & 6 & 48 & 0.7 & \\
\hline Fos-Nit-Aug-Gen- Ofl-Chl-Amo & 7 & 1 & 0.8 & \\
\hline Str-Aug-Gen-Ofl-Tet-Chl-Amo & 7 & 1 & 0.8 & \\
\hline Nit-Aug-Gen-Ofl-Tet-Chl-Amo & 7 & 30 & 0.8 & \\
\hline Str-Nit-Aug-Gen-Ofl-Tet-Chl-Amo & 7 & 10 & 0.9 & \\
\hline Fos-Nit-Aug-Gen-Ofl-Tet-Chl-Amo & $\begin{array}{c}8 \text { (Pan-resistant } \\
\text { isolates }\end{array}$ & 116 & 0.9 & \\
\hline Str-Fos-Nit-Aug-Amo-Chl-Gen-Tet-Ofl & $\begin{array}{c}8 \text { (Pan-resistant } \\
\text { isolates) }\end{array}$ & 53 & 1 & \\
\hline Total & & 509 isolates & & 509 Isolates \\
\hline
\end{tabular}

Ojeniyi (1989) reported 100\% resistance to Tet and Str but $0 \%$ resistance to both $\mathrm{Chl}$ and Nit amongst faecal $E$. coli from intensively managed exotic chickens at Ibadan,
SW Nigeria while in faecal E. coli from free-range chickens from the same area, there was almost no resistance to Tet and Str $(96 \%$ and $98 \%$ susceptibilities 
respectively), and $0 \%$ resistance to $\mathrm{Chl}$ and Nit. This high level resistance to Tet and Str observed for faecal $E$. coli of intensively managed chickens 20 years prior to our study, may be due to the decades-long use of these 2 antibiotics as feed additives, and brooding medications for day-old chicks in Nigeria. On the other hand, Nit and Chl were introduced as poultry medications more recently, a factor that might have been responsible for the total susceptibility of faecal $E$. coli from intensive- and freerange chickens to these 2 antibiotics. Although, the scarcer and more expensive quinolones were not tested at all in the 1989 study, our results show that by 2009, $86.4 \%$ of APEC isolates from SW Nigeria were resistant to Ofl, a finding similar to the $85-100 \%$ reported by Raji et al. (2007) for APEC isolates from 2 farms in northern Nigeria. To investigate the current Str-resistance status of APEC isolates from SW Nigeria, a disc concentration of $200 \mu \mathrm{g}$ of Str, equivalent to a 10-fold increase in the usual disc concentration reported for the gel diffusion test was chosen. Remarkably, $14.3 \%$ of the APEC isolates were still resistant to this high concentration of Str.

The results of this study show that $84.68 \%$ (431 out of 509 isolates) of the APEC isolates from SW Nigeria were MDR phenotypes. This high aggregate prevalence of MDR E. coli isolates in SW Nigeria is similar to the findings reported by Ogunleye et al. (2008) for eleven commercial poultry farms in Abeokuta, Ogun State, and also to recent trends within the same area as reported by Ojo et al. (2012), for apparently healthy free-range birds in which faecal $E$. coli were resistant to chloramphenicol $(73.1 \%)$, streptomycin $(80.8 \%)$, tetracycline $(76.9 \%)$ and quinolones (34.6-61.5\%). Our findings of very high levels of APEC prevalence to tetracycline (91.4\%), chloramphenicol $(96.5 \%)$, Amoxicillin $(99.2 \%)$ and the second generation Class-II quinolone Ofloxacin (86.4\%), raise a moral question about the continued importation, marketing, and use of these drugs as poultry medications in Nigeria.

Results (Table 3) show that about one-third of all APEC isolates from SW Nigeria are pan-resistant to eight different classes of antibacterial drugs represented by the nine antibiotics tested in the agar gel diffusion test. This finding is disturbing because 5 of those antibiotics (Amo, Aug, Gen, Nit and Tet) belong to the current list of essential antibacterial drugs meant for human use in Nigeria (Federal Ministry of Health of Nigeria, 2010). Essential drugs for countries are selected based on prevailing health conditions, drug efficacy, safety, quality, and cost-effectiveness and government budgetary allocations for the health sector. In Nigeria, unqualified persons including farmers, continue to engage in the empirical treatment of poultry infections with popular antibiotics, based on the presumed susceptibility of causative strains.

Poultry farmers in Nigeria often resort to the use of antibiotic cocktails comprised of several human and veterinary preparations, when conventional poultry drugs fail to mitigate the symptoms of disease. According to Glynn et al. (1999), MDR bacteria arising from the misuse of antibiotics in animal production systems, may select for drug resistant zoonotic bacteria such as Salmonella and Campylobacter. Poultry and livestock infections due to MDR bacteria lead to higher morbidities and prolonged treatment of sick animals, higher treatment failure rates and mortalities, and costly drug changes that add to the production costs for meat, dairy and eggs, and lower farmers' profits. Similarly, MDR bacteria have grave implications for public health in terms of higher morbidities, prolonged hospitalizations, the need for use of newer and expensive drugs, and the greater risk of mortalities in the elderly and infants.

\section{CONCLUSION}

A holistic approach is required for the prevention and control of avian colibacillosis in SW Nigeria and other regions of the country and this will require the active involvement and cooperation of farmers, hatchery operators, drug importers and marketers, veterinary and allied professionals, and government regulatory agencies at all levels. Hatcheries must be required to undergo regular and mandatory hygiene audits and quality control checks to ensure stricter compliance to disinfection procedures that can prevent cross-over infections between hatches. To operate, hatcheries must possess government certified reports of such audits. To detect vertically transmitted APEC infections, chicks must be screened early in life and affected batches should be traced-back to source (e.g. the hatchery and breeder flock of origin). The benefits of sanitization of farm water supplies cannot be overemphasized, and lines should be flushed with high concentration of water sanitizers to dislodge accumulated slime which protect bacteria. Veterinary extension agencies in Nigeria need to address the patent need for mass awareness campaigns that sensitize poultry and livestock farmers and feed millers, on the long term benefits of rational administration of antibiotics to farm animals.

There is need for stricter enforcement of section 6.23 of the National Drug Policy, the extant law that guides the procurement, distribution, supply and utilization of veterinary drugs in Nigeria (National Drug Policy, 2003). Subsection 5 of the law requires that veterinary drugs should be dispensed based on prescriptions given by authorized and registered veterinary practitioners. In view of the high prevalence of pan-resistant APEC strains in SW Nigeria, there is a need to explore other treatment options that provide an alternative to antibiotics. For example, commercially available probiotics or organic acids in finished feed. The development of an autochtonous polyvalent vaccine that contains the most prevalent APEC strains from the region may still be the best long term solution to the prevention of avian colibacillosis in chickens and other poultry.

\section{REFERENCES}

Adeleke, E. O. and Omafuvbe, B. O. (2011). Antibiotic resistance of aerobic mesophilic bacteria isolated from poultry faeces. Research Journal of Microbiology 6, 356-365.

Adene, D. F. and Oguntade, A. E. (2006). The structure and importance of the commercial and village based poultry industry in Nigeria. In: Nigerian Poultry Sector Report. Food and Agriculture Organisation (FAO), Rome, Italy. pp. 102. 
Alo, O. S. and Ojo, O. (2007). Use of antibiotics in food animals: A case of a major veterinary outlet in Ekiti State, Nigeria. Nigerian Veterinary Journal 28(1), 8082.

Altekruse, S. F., Elvinger, F., Lee, K. Y., Tollefson, L. K., Pierson, E. W., Eifert, J. and Sriranganathan, N. (2002). Antimicrobial susceptibilities of Escherichia coli strains from a turkey operation. Journal of the American Veterinary Medical Association 221, 411416.

Bager, F., Madsen, M., Christensen, J. and Aarestrup, F. M. (1997). Avoparcin used as a growth promoter is associated with the occurrence of vancomycinresistant Enterococcus faecium on Danish poultry and pig farms. Preventive Veterinary Medicine 31(12), 95-112.

Barnes, H. A. and Gross, W. B. (1997). Colibacillosis. In: Disease of Poultry. $10^{\text {th }}$ edn. Calnek, B. W., Barnes, H. J., Beard, C. W., McDougald, L. R., and Saif, Y. M. (eds.). Mosby-Wolf Publication Ltd, London. pp. 131139.

Barnes, H. J., Vaillancourt, J. and Gross, W. B. (2003). Colibacillosis. In: Diseases of Poultry. Saif, Y. M. (ed.). $11^{\text {th }}$ edn. lowa State Press, lowa. pp. 631-652

Brown, P. K. and Curtiss III, R. (1996). Unique chromosomal regions associated with virulence of an avian pathogenic Escherichia coli strain. Proceedings of the National Academy of Sciences, USA 93, 11149-11154.

Clinical Laboratory Standards Institute (2006). Performance standards for antimicrobial susceptibility testing. $9^{\text {th }}$ edn. Clinical Laboratory Standards Institute, Wayne, PA. M2-A9.

Dalet D. (2013). Federal Republic of Nigeria Map showing boundaries, states, names. Accessed online at http://d-maps.com/m/africa/nigeria/nigeria21.gif [Accessed on 23/07/2013].

Dashe, Y. G., Kazeem, H. M., Abdu, P. A., Abiayi, E. A., Moses, G. D., Barde, I. J. and Jwander, L. D. (2012). Distribution of aerobic bacteria in visceral organs of poultry affected by highly pathogenic avian influenza (H5N1) in Nigeria. Journal of American Science 8(3), 745-748.

Dho-Moulin, M. and Fairbrother, J. M. (1999). Avian pathogenic Escherichia coli. Veterinary Research 30, 299-316.

Ewers, C., Janssen, T. and Wieler, L. H. (2003). Avian Escherichia coli (APEC). Berliner und Munchener Tierarztliche Wochenschrifterl 116, 381-395.

Ezekiel, C. N., Olarinmoye, A. O., Oyinloye, J. M. A., Olaoye, O. B. and Edun, A. O. (2011). Distribution, antibiogram and multidrug resistance in Enterobacteriaceae from commercial poultry feeds in Nigeria. African Journal of Microbiology Research 5(3), 294-301.

Federal Ministry of Health of Nigeria (2010). Essential Medicines List Fifth Revision. Federal Ministry of Health Abuja, Nigeria In Collaboration with World Health Organization and European Commission. pp. 14-15.

Glynn, M. K., Bopp, C., Dewitt, W., Dabney, P., Mokhtar, M. and Angulo, F. J. (1999). Emergence of multidrug-resistant Salmonella enterica serotype typhimurium DT104 infections in the United States. The New England Journal of Medicine 338, 13331338.

Gross, W. G. (1994). Diseases due to Escherichia coli in poultry. In: Escherichia coli in domestic animals and humans. Gyles, C. L. (ed.). Centre for Agricultural Bioscience International, Wallingford, United Kingdom. pp. 237-259.

Hasan, B., Faruque, R., Drobni, M., Waldenström, J., Sadique, A., Ahmed, K. U., Islam, Z., Parvez, M. B. H., Olsen, B. and Alam, M. (2011). High prevalence of antibiotic resistance in pathogenic Escherichia coli from large- and small-scale poultry farms in Bangladesh. Avian Diseases 55(4), 689-692.

Huff, G. R., Huff, W. E., Balog, J. M., Rath, N. C., Anthony, N. B. and Nestor, K. E. (2005). Stress response differences and disease susceptibility reflected by heterophil to lymphocyte ratio in turkeys selected for increased body weight. Poultry Science 84, 709-717.

lloeje, N. P. (2001). A New Geography of Nigeria. Longman Nigeria Ltd., Nigeria. pp. 200.

Johnson, T. J., Logue, C. M., Johnson, J. R., Kuskowski, M. A., Sherwood, J. S., Barnes, H. J., DebRoy, C., Wannemuehler, Y. M., ObataYasuoka, M., Spanjaard, L. and Nolan, L. K. (2012). Associations between multidrug resistance, plasmid content, and virulence potential among extraintestinal pathogenic and commensal Escherichia coli from humans and poultry. Foodborne Pathogens and Disease 9(1), 37-46.

Krumperman, P. H. (1983). Multiple antibiotic resistance indexing of Escherichia coli to identify high-risk sources of fecal contamination of foods. Applied and Environmental Microbiology 46(1), 165-170.

Lowenstine, L. J. (1986). Necropsy procedures. In: Clinical Avian Medicine and Surgery. Harrison, G. J., and Harrison, L. R. (eds.). W. B. Saunders, Philadelphia, PA, USA. pp. 298-309.

Mamza, S. A., Egwu, G. O. and Mshelia, G. D. (2010). Antibiotic susceptibility patterns of beta-lactamaseproducing Escherichia coli and Staphylococcus aureus isolated from chickens in Maiduguri (Arid zone), Nigeria. Veterinarski Arhiv 80, 283-297.

Mellata, M., Dho-Moulin, M., Dozois, C. M., Curtiss III, R., Lehoux, B. and Fairbrother, J. M. (2003). Role of avian pathogenic Escherichia coli virulence factors in bacterial interaction with chicken heterophils and macrophages. Infection and Immunity 71, 494-503.

National Drug Policy (2003). Control of veterinary drugs (First Revision). Federal Ministry of Health Nigeria in Collaboration with World Health Organization, Geneva. pp. 30-31.

National Population Commission (2010). Federal Republic of Nigeria 2006 population and housing census priority table Volume III (Population distribution by sex, state, local government area and senatorial district). National Population Commission, No. 1 Masaka Close, off Olusegun Obasanjo Way, Wuse Zone 7, Abuja, Nigeria. pp. 16-18.

Niilo, L. and Bezeau, L. M. (1961). Experiments with Pseudomonas aeruginosa on vitamin A deficient 
Mal. J. Microbiol. Vol 9(4) 2013, pp. 317-325

chickens. Canadian Journal of Comparative Medicine and Veterinary Science 25, 42-44.

Nivas, S. C., Peterson, A. C., York, M. D., Pomeroy, B. S., Jacobson, L. D. and Jordan, K. A. (1977). Epizootiological investigations of colibacillosis in turkeys. Avian Diseases 21, 514-530.

Ogunleye, A. O., Oyekunle, M. A. and Sonibare, A. O. (2008). Multidrug resistant Escherichia coli isolates of poultry origin in Abeokuta, South Western Nigeria. Veterinarski Arhiv 78, 501-509.

Ojeniyi, A. A. (1989). Direct transmission of Escherichia coli from poultry to humans. Epidemiology and Infection 103(3), 513-522.

Ojo, O. E., Ogunyinka, O. G., Agbaje, M., Okuboye, J. O., Kehinde, O. O. and Oyekunle, M. A. (2012). Antibiogram of Enterobacteriacae isolated from freerange chickens in Abeokuta, Nigeria. Veterinarski Arhiv 82, 577-589.

Okoli, I. C., Nwosu, C. I., Okoli, G. C., Okeudo, N. J., and Ibekwe, V. (2002). Drug management of antimicrobial resistance in avian bacterial pathogens in Nigeria. International Journal of Environmental Health and Human Development 3(1), 39-48.

Okonko, I. O., Nkang, A. O., Eyarefe, O. D., Abubakar, M. J., Ojezele, M. O. and Amusan, T. A. (2010). Incidence of multi-drug resistant (MDR) organisms in some poultry feeds sold in Calabar Metropolis, Nigeria. British Journal of Pharmacology and Toxicology 1(1), 15-28.

Olarinmoye, A. O, Tayo, G. O. and Akinsoyinu, A. 0. (2011). An overview of poultry and livestock waste management practices in Ogun State, Nigeria. Journal of Food, Agriculture and Environment 9(3\&4), 643-645.

Orajaka, L. J. E. and Mohan, K. (1986). Escherichia coli serotypes isolated from dead-in-shell embryos from Nigeria. Bulletin Animal Health Production for Africa 34, 139-141.

Raji, M., Adekeye, J., Kwaga, J., Bale, J. and Henton, M. (2007). Serovars and biochemical characterization of Escherichia coli isolated from colibacillosis cases and dead-in-shell embryos in poultry in Zaria-Nigeria. Veterinarski Arhiv 77(6), 495-505.

Raji, M. A., Adekeye, J. O, Kwaga, J. K. P. and Bale, J. O. O. (2003). In vitro and in vivo pathogenicity studies of Escherichia coli isolated from poultry in Nigeria. Israel Journal of Veterinary Medicine 58(1), 21-28.

Rodriguez-Siek, K. E., Gidddings, C. W., Doetkott, C., Johnson, T. J. and Nolan, L. K. (2005). Characterizing the APEC pathotypes. Veterinary Research 3(6), 241-256.

Van den Bogaard, A. E. and Stobberingh, E. E. (1999). Antibiotic usage in animals: Impact on bacterial resistance and public health. Drugs 58, 589-607.

Wray, C. and Davies, R. H. (2001). Enterobacteriacae. In: Poultry Diseases. Jordan, F., Pattison, M., Alexander, D. and Faragher, T. (eds.). $5^{\text {th }}$ edn. W. B. Saunders, Philadelphia, PA, USA. pp. 95-130. 